1

\author{
November 5, 2019 \\ submitted to PLOS One
}

\section{The flow of sickle blood through glass capillaries: a point of care application}

short title: Capillary test for sickle cell disease

Christopher D. Brown ${ }^{1}$, Alexey M. Aprelev ${ }^{1}$, and Frank A. Ferrone ${ }^{1 *}$

${ }^{1}$ Department of Physics, Drexel University, Philadelphia, PA 19104 email: fferrone@drexel.edu 


\section{Abstract}

28 We show that the characteristic time for sickled blood to traverse $100 \mu \mathrm{m}$-diameter glass capillaries

29 can be used as the foundation for a useful point-of-care diagnosis for sickle cell disease. $3.2 \mathrm{~cm}$

30 long capillaries were inserted into a $5 \mu \mathrm{L}$ drop of blood, and $1 / 4 \mu \mathrm{L}$ was spontaneously drawn into

31 the tube. The rate at which the blood traversed the capillary was significantly changed by

32 deoxygenation only for sickle genotypes, a consequence of the increased viscosity of cells

33 containing sickle fibers. Under these conditions, we find deoxygenation causes the time for sickle

34 blood to traverse the capillary to increase to about 3 times its original value, in contrast to normal

35 blood, where the times are equivalent regardless of state of oxygenation. This corresponds to

36 readily-observed time differences of around $10 \mathrm{~s}$ for capillary traversal. Such changes are present

37 for blood from homozygous sickle cell patients, as well as heterozygous patients with hemoglobin

$38 \mathrm{AS}, \mathrm{SC}$, and $\mathrm{S} \beta^{+}$thalassemia. Moreover, we demonstrate that this test is sensitive to sickling

39 therapies that increase the production of fetal $\mathrm{Hb}$. This viscosity-based measurement thus offers

40 the prospect of an assay that is 10 times faster than any current test of which we are aware, at costs

41 that rival the least expensive of any current assays. 


\section{Introduction}

47 The life expectancy of a child born with Sickle Cell Anemia is drastically dependent on where that

48 child is born. Were the child born in the US, he or she can expect a life-span of around 40 years,

49 on average, [1] but for the same child born in Africa, it is under 5 years. [2] [3] Alas, 79\% of

50 sickle cell newborns are found in sub-Saharan Africa, and by 2050 this is expected to rise to a

51 phenomenal 88\%.[4] The overall standard of medical care will undoubtedly play a role in any

52 lifespan, to be sure, but administration of prophylactic penicillin [5] and pneumococcal vaccination

53 [6] are known to have a profound effect on the life expectancy of sickle cell patients in developing

54 nations, once the children at risk are identified [3]. The tests typically used in the developed world

55 to make this determination, such as isoelectric focusing, or HPLC, not only are prohibitively

56 expensive, but also tend to require highly trained personnel. This makes a simple and rapid test an

57 important goal for public health, especially in regions of high incidence. Indeed, the recognition

58 of the value of a rapid diagnostic test was first realized by no less than Linus Pauling some 70

59 years ago.[7]

60 Sickle Cell Anemia is the most severe of the sickle cell genotypes, since the patient is homozygous

61 for $\mathrm{HbS}$. A variety of heterozygous conditions exist. The most common is to mix one gene for $\mathrm{S}$

62 with one for normal HbA. The AS combination is known as sickle trait, and is largely benign. In

$63 \mathrm{~S} \beta^{+}$thalassemia, one again has a combination of $\mathrm{A}$ and $\mathrm{S}$, but with far less $\mathrm{A}$, and patients with

$64 \mathrm{~S} \beta^{+}$thalassemia suffer from many of the same issues as SS patients $[8,9]$. Finally, combining an

$65 \mathrm{~S}$ gene with one for $\mathrm{HbC}$ produces a phenotype, $\mathrm{SC}$, with severity comparable to that of $\mathrm{S} \beta^{+}$

66 thalassemia $[8,9]$. 
67 The damage inflicted by sickle cells, of any composition, begins when deoxygenation rigidifies

68 the mass of hemoglobin they contain. [10,11] By obstructing the microcirculation, these cells

69 deprive downstream tissues of oxygen, producing organ damage, and painful episodes. Chien et

70 al [13] demonstrated that chemically hardening of the red-cell membrane of normal blood cells by

71 acetaldehyde to make erythrocytes undeformable elevated the viscosity several times, and thus it

72 is unsurprising that cells that cannot deform because of internal rigidity likewise display elevated

73 viscosity, as has been observed for some time.[12] We hypothesized that this induced stiffness

74 could be used as a simple and rapid diagnostic for the presence of the sickle gene. The needs of

75 economy and portability rule out conventional viscometers, but the flow of blood into a small glass

76 capillary might have the requisite properties. We thus were led to explore the flow of whole blood

77 drawn into a $100 \mu \mathrm{m}$-diameter capillary, comparing deoxy blood to its oxygenated counterpart.

78 We find that this simple measurement has great potential, and rests on a solid foundation as shown

79 elsewhere. Sickled (i.e. rigidified) cells flowed through these capillaries significantly more slowly

80 than their flexible counterparts. While this flow can be described as the behavior of a simple fluid

81 with elevated viscosity for much of the flow, the rigid cells were also found to accumulate into a

82 dense zone or cap behind the advancing meniscus, retarding the velocity even further. Although

83 these features appeared in all instances of sickle cell disease, we also observed systematic

84 differences between the different genotypes. In this paper we explore the common features as well

85 as the systematic differences, and show to what extent clinically useful discrimination is possible.

86 The data collected here used cameras and positioning equipment for detailed characterization, but,

87 as we show, visual observation and a simple stopwatch are all that is required for an efficient and

88 inexpensive assay. 
90 Materials and Methods

92 Blood was collected from 23 patients, primarily from St. Christopher's Hospital in Philadelphia.

93 In addition, AA blood was contributed by the investigators, while AS blood was contributed from

94 the laboratory of Dr. W. A. Eaton of the NIH as a discard product from a study underway there.

95 Blood was collected into EDTA anticoagulant in all cases. A $5 \mu \mathrm{L}$ drop was used for the

96 measurements, and in the case of deoxygenated blood, contained $50 \mathrm{mM}$ sodium dithionite. A 100

$97 \mu \mathrm{m}$ diameter Drummond micropipet (1/4 $\mu \mathrm{L}$ volume) was horizontally inserted into the drop, and

98 the transit of the blood was recorded as it was drawn into the capillary micropipet. The position

99 of the blood is readily observed by the unaided eye, however, and the recording was simply done

100 for our own ancillary analysis of the flow, but is not essential to the method. All deoxygenated

101 samples had their state of deoxygenation verified by a spectrophotometer described elsewhere,

102 immediately following the transit measurement.

\section{Results}

105 Typical data is shown in Fig. 1, which displays oxygenated and deoxygenated sickle blood in 106 transit through the capillary. The flow of AA blood is the same for both oxygenated and 107 deoxygenated blood. The transit for oxygenated blood from a Sickle-cell Anemia patient is 108 somewhat faster than AA because the anemia reduces the hematocrit (HCT, the volume taken up 109 by the red cells), and thus makes the solution less viscous. Deoxygenated SS blood not only flows

110 substantially slower, but also eventually forms a dense region of cells behind the meniscus, that 111 causes it to progress even slower. Because the analysis of horizontal flow is simpler than vertical 
112 flow, we collected the majority of this data in the horizontal geometry. However, vertical

113 experiments revealed similar phenomena, viz. the slowed transit of deoxygenated sickle blood and

114 the formation of a dense cap behind the meniscus. The vertical transits were also longer than the

115 horizontal (e.g. $\sim 15$ s vertical vs 10 s horizontal).

117 Fig. 1. Movement of blood drawn into a horizontal capillary after 3 seconds, viewed from

118 above. Capillaries were standard $1 / 4 \mu \mathrm{L}$ Drummond microcaps, approximately $3 \mathrm{~cm}$ long. The

119 oxygenated blood on the left has clearly gone farther in the same time than the deoxygenated blood

120 on the right. A drop of blood is placed on an $18 \mathrm{~mm}$ square coverslip into which a capillary has

121 been inserted. In addition to the blood imbibed into the capillary itself, some blood runs along

122 the space between the capillary and the coverslip, accounting for the odd shape of the source

123 droplet.

125 Fig 2 shows how the time for cell transits varies for a range of genotypes. Each column in the

126 figure displays the data for one individual, with each point designating a single measurement.

127 The oxygenated blood behaves very consistently among the replications, as well as between

128 individuals, regardless of genotype. As mentioned above, a degree of systematic variation is

129 expected since the HCT varies between the genotypes. The dashed horizontal line shows the

130 average oxygenated cell transit time for AA cells. The various sickle cell genotypes, including

131 the patients being treated with hydroxyurea (HU group), have deoxygenated transit times which

132 clearly exceed AA, and also showing greater variability.

133 


\section{Fig. 2. Time for cell transits along a distance of $24 \mathbf{m m}$ in $1 / 4 \mu \mathrm{L}$ glass capillaries, for the}

135 genotypes studied. HU indicates patients being treated with hydroxyurea. Each column in the

136 figure displays the data for one individual, and each point is a single measurement. The various

137 sickle cell genotypes, including the HU group, clearly differ from AA, showing greater variability, 138 and longer transits overall.

140 Another way to display the data of Fig 2 is to designate $\mathrm{x}$ and $\mathrm{y}$ axes as the transit time of the

141 oxygenated and deoxygenated blood, respectively, so that each experiment becomes a point on

142 that plane as shown in Fig 3. Each genotypic cluster (oxygenated and deoxygenated times) was

143 characterized by a mean and standard deviation, the latter effectively displaying the patient-to-

144 patient variation, since there was much less difference between individual replication experiments

145 than seen between different patients. These standard deviations generate the ellipses in Fig. 3,

146 centered on the mean value we obtained for each genotype. An elliptical zone of paired transit

147 times thus emerged as a characteristic fingerprint of the genotype. For AS blood, only one patient

148 was studied, and that ellipse is taken as a representative value from the other data sets.

150 Fig. 3. Transit time profiles. Data points from Figure 2 are displayed, with error bars and means

151 that represent the dispersion and mean of the data from Fig. 2. An elliptical region has been

152 constructed with center at the mean, and semi-major axes representing the standard deviation of

153 that data, for each of the genotypes. Since only one patient was measured for AS, only a dashed

154 ellipse is shown, approximated with axes representative of the group of all genotypes. Each point

155 shown designates data for a single patient, and error bars of the point show the replication error

156 for the particular patient. AA blood is well distinguished. For patients on the drug hydroxyurea 
157 (HU), the data spans the range from the SS to AA, suggesting the utility of this method in rapidly

158 and inexpensively monitoring the response to the drug. It is known that not all patients respond

159 similarly to this drug, which we suspect is the major factor in the range of variation of the HU data.

161 The AA region in Fig. 3 is clearly distinct from the sickling disorders. The region for SS patients

162 shows a significant overlap with that for patients with $\mathrm{S} \beta^{+}$thalassemia, but it is distinct from AS

163 and SC patients.

164 We can generate an estimate of the sensitivity and specificity of this method. To this end, we 165 generated continuous distributions, which had the mean and standard deviations calculated from

166 the discrete data we collected. (For AS, having only one patient we used that mean value but

167 adapted the standard deviation We took standard deviations from the other populations and

168 divided them by their corresponding mean to get percent deviations. We then averaged the

169 oxygenated and the deoxygenated percentages. Finally we multiplied the AS mean by the

170 averaged percent to get estimated population standard deviations. Since such a continuous

171 distribution will extend into regions with negative transit times, which are physically meaningless,

172 we limited the distributions to physically possible values, and adjusted the normalization of the

173 distribution accordingly.

174 The sensitivity of the test for any genotype area is defined as the ratio of true positives to the sum

175 of true positives and false negatives. The specificity of a genotype is defined as the ratio of true

176 negatives to the sum of true negatives and false positives. True positives were calculated by

177 integrating the distribution over the region where it exceeded all other distributions (i.e. over its

178 dominant region), while the false negative was calculated integrating the distribution over all

179 regions except for that where the distribution exceeded all others. For the true negatives and false 
180 positive, the remaining distributions other than the genotype in question were integrated outside

181 or inside the dominant region, respectively. As confirmation of this procedure, we generated a

182 large random set of data with a gaussian distribution, using the given means and standard

183 deviations, and found the results computed agreed to within 2 percent. These results are shown

184 in Table 1, which provides a quantitative measure for what Fig 2 and 3 show intuitively. AA is

185 readily discerned compared with any sickle variant. The same method picks SS correctly about

1862 out of 3 times, confusing it most often with $\mathrm{S} \beta^{+}$thalassemia.

187

188

189

190

191

192

193 We have also measured blood from patients who are being treated with the drug Hydroxyurea

194 (HU), one of the two drugs approved for sickle cell disease [14]. HU increases the production of

195 Fetal Hb, which is incapable of polymerization [12], and modestly increases the HCT from 25 to

$19627 \%$. [14] The final panel of Fig 3 shows the timing profile we measured in 6 sickle patients

197 currently on HU. The profile extends from the top of SS toward that of AA patients. (We did not

198 include HU patients in the specificity and sensitivity calculations since such patients, ipso facto,

199 already have their genotype identified.)

200 Since the basis of this test is the difference in the viscosity of sickle blood, we also show how the 201 viscosity varies for the various genotypes. Figure 4a is a "fingerprint" analogous to Fig. 3, with 
202 viscosity shown instead of transit time for deoxygenated vs oxygenated blood. As found for

203 simple timing measurements, so too for viscosity: the AA genotype is well distinguished. If the

204 deoxygenated viscosity is normalized by the oxygenated viscosity and the ratio is plotted, the result,

205 in Fig 4b, shows remarkable similarity amongst the various genotypes. The factor of increase in

206 viscosity for undeformable sickle cells is, within error, the same ratio as seen upon the

207 rigidification of AA red cells, shown by Chien et al. [13] From this one may conclude that it is

208 the transformation of flexible cells to rigid particles which dominates the ratio, irrespective of the

209 shape the particles may have assumed when they lost their deformability.

211 Fig. 4. Viscosity and viscosity-ratio profiles. (a) Viscosity has been deduced from the data

212 shown in Fig 2 and 3. Deoxygenated viscosity is plotted as a function of oxygenated viscosity for

213 the various genotypes as well as patients on HU. As for Fig. 3, AA blood is well distinguished.

214 (b) Ratios of deoxygenated to oxygenated viscosity, shown as a function of oxygenated viscosity.

215 The ratio and its standard deviation are remarkably consistent among the sickle genotypes.

\section{Discussion}

218 It is apparent that the sickling genotypes can clearly be distinguished from normal AA blood by

219 the method shown here. A quantitative analysis gives a 98\% true positive rate for distinguishing

220 AA patients from those who possess the sickle gene. The other genotypes are distinguishable from

221 one another to varying degrees, though all are distinct from AA blood. SS and $\mathrm{S}^{+}$thalassemia

222 differ from AS and SC, primarily based on their hematocrit dependence. However, AS and SC

223 are quite similar in this test, as are $\mathrm{SS}$ and $\mathrm{S} \beta^{+}$thalassemia. 
224 The use of paired oxy and deoxy values in Fig. 3 avoids a number of potentially confounding

225 issues. For example, polycythemia vera generates high hematocrits. These would increase

226 viscosity and thus slow the transit of blood through the test capillary. However, the concomitant

227 increase in the viscosity of oxy and deoxy blood differs from the sickling disorders where only

228 deoxygenated blood increases. In Fig 3, such a disorder of increased viscosity would displace the

229 AA points diagonally upward, whereas SS displaces these points almost vertically (with a slight

230 left shift). In a similar fashion, the presence of malarial parasites would increase viscosity of oxy

231 and deoxy cells alike [15]. Moreover, the viscosity increase from malaria is also more modest than

232 observed here. Finally, the same rationale applies to temperature effects. The viscosity of blood

233 decreases about $30 \%$ as temperature is raised from $25^{\circ} \mathrm{C}$ to $45^{\circ} \mathrm{C}$ [15]. The temperature

234 dependence is the same as that of water [16], and the temperature changes would again move data

235 diagonally along the plot.

236 The use of a vertical geometry for the capillary insertion into the drop would serve to enhance

237 resolution further. It is straightforward to show (cf paper 1, eq 1) that to traverse a given capillary

238 length, deoxy blood takes longer than oxy blood by the same factor, independent of vertical or

239 horizontal alignment. But, since vertical rise is intrinsically slower (thanks to gravity opposing

240 capillarity), the differences are amplified in the vertical direction. Vertical insertion into a drop of

241 blood would likely be more easily arranged for day to day clinical study.

242 The present data are taken by initial deoxygenation in a vial using sodium dithionite solution,

243 followed by extraction of a $5 \mu \mathrm{L}$ drop. However, that technique was devised for laboratory

244 convenience, not field use, and it is not hard to imagine the development of pre-loaded vials, or

245 other methods (such as using other dithionite-laden capillaries for deoxygenation) as a first step to

246 expedite and simplify this procedure. Likewise, although we obtained detailed data with a small 
247 camera the same diagnostic value is readily obtained by measuring the transit time to some fixed

248 distance, which can be done by visual observation and stopwatch timing (c.f. SI Fig. 1).

249 It is useful to compare this capillary test to the handful of other point of care tests. Four such tests

250 have been published and have been reviewed in detail. [17].

251 In the first of those four tests, a drop of lysed, deoxygenated blood is placed on a paper and the

252 diffusion of the deoxygenated hemoglobin is observed. [18-22] Polymerized HbS is relatively

253 immobile compared to $\mathrm{HbA}$, and $\mathrm{AS}$ has a mix of sickled and unsickled $\mathrm{Hb}$ with the result that

254 these three genotypes can be distinguished, as with the metric shown here. The test requires the

255 mixing of $20 \mu \mathrm{L}$ of blood with sickledex solution, followed by a wait of about 35 minutes after

256 application of the drops to the paper. Similar to our findings, AS and SC are difficult to distinguish,

257 as are $\mathrm{SS}$ and $\mathrm{S} \beta^{+}$thalassemia.[22] In comparison to such a paper test, the capillary method has

258 similar discrimination, is equally inexpensive, but is dramatically faster since the rise in the

259 capillaries is complete in seconds, not minutes.

260 Two tests of greater accuracy use antibody-based methods. Both begin with cell lysis. One test

261 using monoclonal antibodies [23] distinguishes AA, SS, AS and SC. This discrimination is

262 superior to the capillary test, though the antibody mis-diagnoses $\mathrm{S} \beta^{+}$thalassemia as AS. The test

263 takes typically 20 minutes. A different immunoassay [24] successfully resolves the all the

264 foregoing genotypes as well as $\mathrm{S} \beta^{+}$thal, and succeeds in obtaining results in as little as 2 minutes

265 after mixing the drawn blood drop with lysing agents, albeit at a cost of around \$5 [17]. In

266 comparison, the other two methods are ten times less expensive.

267 The fourth test described is a density-based system that does not require cell lysis. [25, 26]

268 Aqueous Multiphase Systems (AMPS) are mixtures of polymers in water that form immiscible 
phases, and have been used with centrifugation with to reveal the presence of high-density cells

270 that are a hall-mark of sickle cell disease. Of course, the method would not distinguish AS from

271 AA, and also might be confounded by things such as liver disease or polycythemia vera that

272 generate denser cells. This system, considered to take 12 minutes, requires the presence of a

273 centrifuge, and given the inefficiency of running a solo tube, would likely mean tests are done in

274 batches.

275 None of these methods match the combination of time resolution inherent in the capillary-based

276 system (20 sec for the two measurements) and its low cost. The cost of the paper-based system

277 might be comparable, but it takes far longer. The polyclonal antibody system is speedy but is

278 still $\sim 6$ times slower, and at $\$ 5$ per test is far more costly than the capillary test. An optimal

279 approach for diagnosis in resource-challenged regions might combine methods. Capillary flow as

280 a pre-screen can rapidly and inexpensively sort AA patients from their sickle counterparts, for

281 whom a follow-up test at higher cost might be appropriate. The value of such a strategy can be

282 appreciated by considering places where the incidence is very high, such as Nigeria. There the S

283 allele appears in about only $20 \%$ of the population [4], so that $80 \%$ of the tests performed in a

284 general screen would reveal a non-S patient. For other nations with lower incidence, an even

285 greater percentage of tests would be expected to have negative results. For this reason a rapid and

286 inexpensive pre-screen could be very useful.

287 There is also information present in capillary tests that is simply not present in the antibody tests.

288 As the final panel of Fig 3 shows, the behavior of blood for SS patients taking hydroxyurea

289 stretches between the region of SS and that of AA, yet the different patients responded differently.

290 Response of different patients to HU differs $[17,27]$. The data of Fig 2 shows that different

291 patients on HU have dramatically different deoxygenated blood transits. For some it is virtually 
292 identical to AA cells; for others it is much more like untreated SS blood. Having a rapid and

293 inexpensive metric that could track such a response could be very useful.

294 An important question is whether the accuracy of the method can be improved. From Fig. 2 it is

295 evident that the patient-to-patient variation is far greater than the variability of measurements on

296 an individual patient. This is dramatically evident in the SC patients. Interestingly, when the

297 measurement was repeated on the same AS patient after several months, the range of variation was

298 virtually identical. We suspect the range of variability in SC and, by extension, AS, is a

299 consequence of the complexity of the sickling process itself. The shapes of the sickled cells can

300 range from the classic, extended eponymous sickle form to compact yet rigid cells that have been

301 said to resemble potatoes. These shapes are exquisitely sensitive to the rate at which

302 polymerization occurs, [28] which in turn depends on the cellular contents as well as the rate of

303 deoxygenation. In particular, heterozygous conditions produce far greater distortions in the

304 sickled cells than homozygous SS cells, a fact which is utilized in a current drug assay. [29] The

305 differences within a given genotype might well be the consequence of the history of a given patient

306 that shaped the particular cellular population at the time of observation. While this variable is

307 viewed as confounding in the attempt to ascertain the presence of the $\mathrm{S}$ allele, it might actually

308 provide unexpected insights, to the extent that the patients with longer transits might have a more

309 severe course of the disease.

310 In this context, it is a welcome bonus that this test provides a snapshot of patient response to

311 hydroxyurea. Response to this drug has proven to be quite variable. [27] The last panel of Fig 3

312 demonstrates this, as it is clear that the upper end of the distribution of deoxy transit times contains

313 times equivalent to those of SS patients, suggesting the lack of any significant response to the drug.

314 On the other hand, the low end of the distribution falls decidedly below that of SS patients, 
315 suggesting that these are the higher responders. (Due to the nature of our protocol, we had no

316 other data that described the patients' severity of clinical course.) Further testing is required to

317 show whether this rapid point of care test might assist in providing feedback to patients and their

318 physicians when this or other anti-sickling agents are in use.

321 ACKNOWLEDGEMENTS We thank Michelle Cahill and Dr. Nataly Apolonsky, of St. Christopher's Hospital for Children,

322 for provisions of samples and continued generous cooperation in support of this project, and Dr. William Eaton, of

323 the Laboratory of Chemical Physics, NIDDKD, NIH, for providing us with valuable advice as well as discard AS blood.

324

\section{References}

327 1. Lanzkron S, Carroll CP, Haywood C, Jr. Mortality rates and age at death from sickle cell

328 disease: u.s., 1979-2005. Public health reports. 2013;128(2):110-6. PubMed PMID:

$32923450875 ;$ PubMed Central PMCID: PMC3560868.

330 2. Serjeant GR. One hundred years of sickle cell disease. Br J Haematol.

331 2010;151(5):425-9. Epub 2010/10/20. doi: 10.1111/j.1365-2141.2010.08419.x. PubMed

332 PMID: 20955412.

333 3. Piel FB, Hay SI, Gupta S, Weatherall DJ, Williams TN. Global burden of sickle cell

334 anaemia in children under five, 2010-2050: modelling based on demographics, excess 335 mortality, and interventions. PLoS medicine. 2013;10(7):e1001484. doi: 
10.1371/journal.pmed.1001484. PubMed PMID: 23874164; PubMed Central PMCID:

338 4. Piel FB, Patil AP, Howes RE, Nyangiri OA, Gething PW, Dewi M, et al. Global 339 epidemiology of sickle haemoglobin in neonates: a contemporary geostatistical model-based

340 map and population estimates. Lancet. 2013;381(9861):142-51. doi: 10.1016/S0140-

341 6736(12)61229-X. PubMed PMID: 23103089; PubMed Central PMCID: PMC3547249.

342 5. Gaston MH, Verter JI, Woods G, Pegelow C, Kelleher J, Presbury G, et al. Prophylaxis

343 with oral penicillin in children with sickle cell anemia. A randomized trial. N Engl J Med.

344 1986;314(25):1593-9. doi: 10.1056/NEJM198606193142501. PubMed PMID: 3086721.

345 6. Halasa NB, Shankar SM, Talbot TR, Arbogast PG, Mitchel EF, Wang WC, et al. Incidence

346 of invasive pneumococcal disease among individuals with sickle cell disease before and after

347 the introduction of the pneumococcal conjugate vaccine. Clinical infectious diseases : an

348 official publication of the Infectious Diseases Society of America. 2007;44(11):1428-33. doi:

349 10.1086/516781. PubMed PMID: 17479937.

350 7. Itano HA, Pauling L. A rapid diagnostic test for sickle cell anemia. Blood. 1949;4(1):66-

351 8. Epub 1949/01/01. PubMed PMID: 18103217.

352 8. Powars DR, Hiti A, Ramicone E, Johnson C, Chan L. Outcome in hemoglobin SC disease:

353 a four-decade observational study of clinical, hematologic, and genetic factors. Am J Hematol.

354 2002;70(3):206-15. doi: 10.1002/ajh.10140. PubMed PMID: 12111766.

355 9. Serjeant GR, Serjeant BE, Fraser RA, Hambleton IR, Higgs DR, Kulozik AE, et al. Hb S-

356 beta-thalassemia: molecular, hematological and clinical comparisons. Hemoglobin.

357 2011;35(1):1-12. doi: 10.3109/03630269.2010.546306. PubMed PMID: 21250876. 
358 10. Zakharov M, Aprelev A, Turner MS, Ferrone FA. The Microrheology of Sickle

359 Hemoglobin Gels. Biophys J. 2010;99(4):1149-56.

360 11. Aprelev A, Stephenson W, Noh HM, Meier M, Ferrone FA. The physical foundation of

361 vasoocclusion in sickle cell disease. Biophys J. 2012;103(8):L38-40. Epub 2012/10/23. doi:

362 S0006-3495(12)01015-6 [pii]

363 10.1016/j.bpj.2012.09.003. PubMed PMID: 23083726.

364 12. Eaton WA, Hofrichter J. Sickle Cell Hemoglobin Polymerization. Adv Protein Chem. $3651990 ; 40: 63-280$.

366 13. Chien S, Usami S, Dellenback RJ, Gregersen MI. Blood viscosity: influence of

367 erythrocyte deformation. Science. 1967;157(3790):827-9. Epub 1967/08/18. doi:

368 10.1126/science.157.3790.827. PubMed PMID: 17842793.

369 14. Charache S, Barton FB, Moore RD, Terrin ML, Steinberg MH, Dover GJ, et al.

370 Hydroxyurea and sickle cell anemia. Clinical utility of a myelosuppressive "switching" agent.

371 The Multicenter Study of Hydroxyurea in Sickle Cell Anemia. Medicine (Baltimore).

372 1996;75(6):300-26. PubMed PMID: 8982148.

373 15. Scherer EF, Cantarini DG, Siqueira R, Ribeiro EB, Braga EM, Honorio-Franca AC, et al.

374 Cytokine modulation of human blood viscosity from vivax malaria patients. Acta tropica.

375 2016;158:139-47. doi: 10.1016/j.actatropica.2016.03.001. PubMed PMID: 26948901.

376 16. Merrill EW, Gilliland ER, Cokelet G, Shin H, Britten A, Wells RE, Jr. Rheology of human

377 blood, near and at zero flow. Effects of temperature and hematocrit level. Biophys J.

378 1963;3:199-213. PubMed PMID: 13935042; PubMed Central PMCID: PMC1366440.

379 17. Alapan Y, Fraiwan A, Kucukal E, Hasan MN, Ung R, Kim M, et al. Emerging point-of380 care technologies for sickle cell disease screening and monitoring. Expert review of medical 
381 devices. 2016;13(12):1073-93. doi: 10.1080/17434440.2016.1254038. PubMed PMID:

383 18. Piety NZ. Traveling to Angola to Validate a Paper-Based Sickle Cell Disease Test. IEEE

384 pulse. 2017;8(3):45. doi: 10.1109/MPUL.2017.2683438. PubMed PMID: 28534764.

385 19. Piety NZ, George A, Serrano S, Lanzi MR, Patel PR, Noli MP, et al. A Paper-Based Test

386 for Screening Newborns for Sickle Cell Disease. Scientific reports. 2017;7:45488. doi:

387 10.1038/srep45488. PubMed PMID: 28367971; PubMed Central PMCID: PMC5377336.

388 20. Piety NZ, Shevkoplyas SS. Paper-Based Diagnostics: Rethinking Conventional Sickle

389 Cell Screening to Improve Access to High-Quality Health Care in Resource-Limited Settings.

390 IEEE pulse. 2017;8(3):42-6. doi: 10.1109/MPUL.2017.2678658. PubMed PMID: 28534763.

391 21. Piety NZ, Yang X, Lezzar D, George A, Shevkoplyas SS. A rapid paper-based test for 392 quantifying sickle hemoglobin in blood samples from patients with sickle cell disease. Am J

393 Hematol. 2015;90(6):478-82. doi: 10.1002/ajh.23980. PubMed PMID: 25689370; PubMed

394 Central PMCID: PMC4439389.

395 22. Yang X, Kanter J, Piety NZ, Benton MS, Vignes SM, Shevkoplyas SS. A simple, rapid, 396 low-cost diagnostic test for sickle cell disease. Lab Chip. 2013;13(8):1464-7. doi: 397 10.1039/c3lc41302k. PubMed PMID: 23429713.

398 23. McGann PT, Tyburski EA, de Oliveira V, Santos B, Ware RE, Lam WA. An accurate and 399 inexpensive color-based assay for detecting severe anemia in a limited-resource setting. Am 400 J Hematol. 2015;90(12):1122-7. doi: 10.1002/ajh.24180. PubMed PMID: 26317494; 401 PubMed Central PMCID: PMC5144537. 
402 24. Kanter J, Telen MJ, Hoppe C, Roberts CL, Kim JS, Yang X. Validation of a novel point of

403 care testing device for sickle cell disease. BMC medicine. 2015;13:225. doi: 10.1186/s12916-

404 015-0473-6. PubMed PMID: 26377572; PubMed Central PMCID: PMC4573998.

405 25. Kumar AA, Chunda-Liyoka C, Hennek JW, Mantina H, Lee SY, Patton MR, et al.

406 Evaluation of a density-based rapid diagnostic test for sickle cell disease in a clinical setting

407 in Zambia. PLoS One. 2014;9(12):e114540. doi: 10.1371/journal.pone.0114540. PubMed

408 PMID: 25490722; PubMed Central PMCID: PMC4260838.

409 26. Kumar AA, Patton MR, Hennek JW, Lee SY, D'Alesio-Spina G, Yang X, et al. Density-

410 based separation in multiphase systems provides a simple method to identify sickle cell

411 disease. Proc Natl Acad Sci U S A. 2014;111(41):14864-9. doi: 10.1073/pnas.1414739111.

412 PubMed PMID: 25197072; PubMed Central PMCID: PMC4205650.

413 27. Steinberg MH, Lu ZH, Barton FB, Terrin ML, Charache S, Dover GJ. Fetal hemoglobin

414 in sickle cell anemia: determinants of response to hydroxyurea. Multicenter Study of 415 Hydroxyurea. Blood. 1997;89(3):1078-88. PubMed PMID: 9028341.

416 28. Christoph GW, Hofrichter J, Eaton WA. Understanding the shape of sickled red cells.

417 Biophys J. 2005;88(2):1371-6. PubMed PMID: 15542552.

418 29. Li Q, Henry ER, Hofrichter J, Smith JF, Cellmer T, Dunkelberger EB, et al. Kinetic assay

419 shows that increasing red cell volume could be a treatment for sickle cell disease. Proc Natl

420 Acad Sci U S A. 2017;114(5):E689-E96. doi: 10.1073/pnas.1619054114. PubMed PMID:

421 28096387; PubMed Central PMCID: PMC5293101.

422

423 


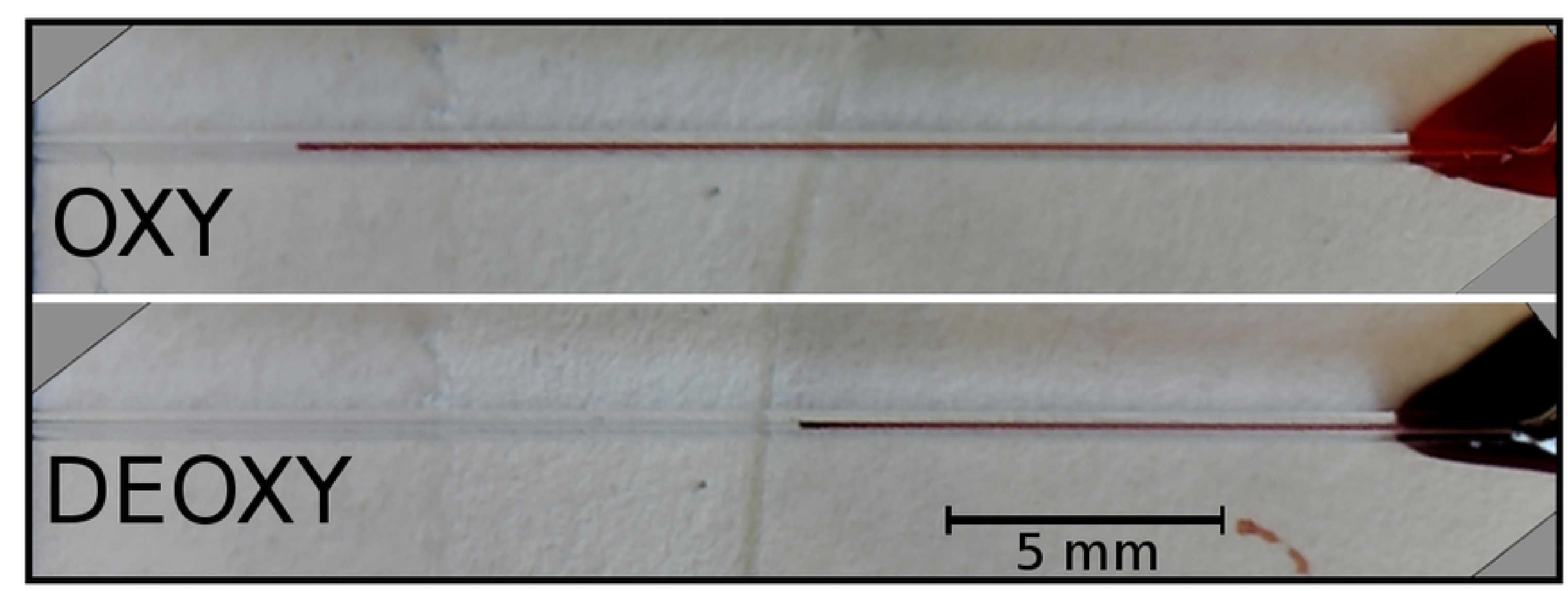

Figure 1 


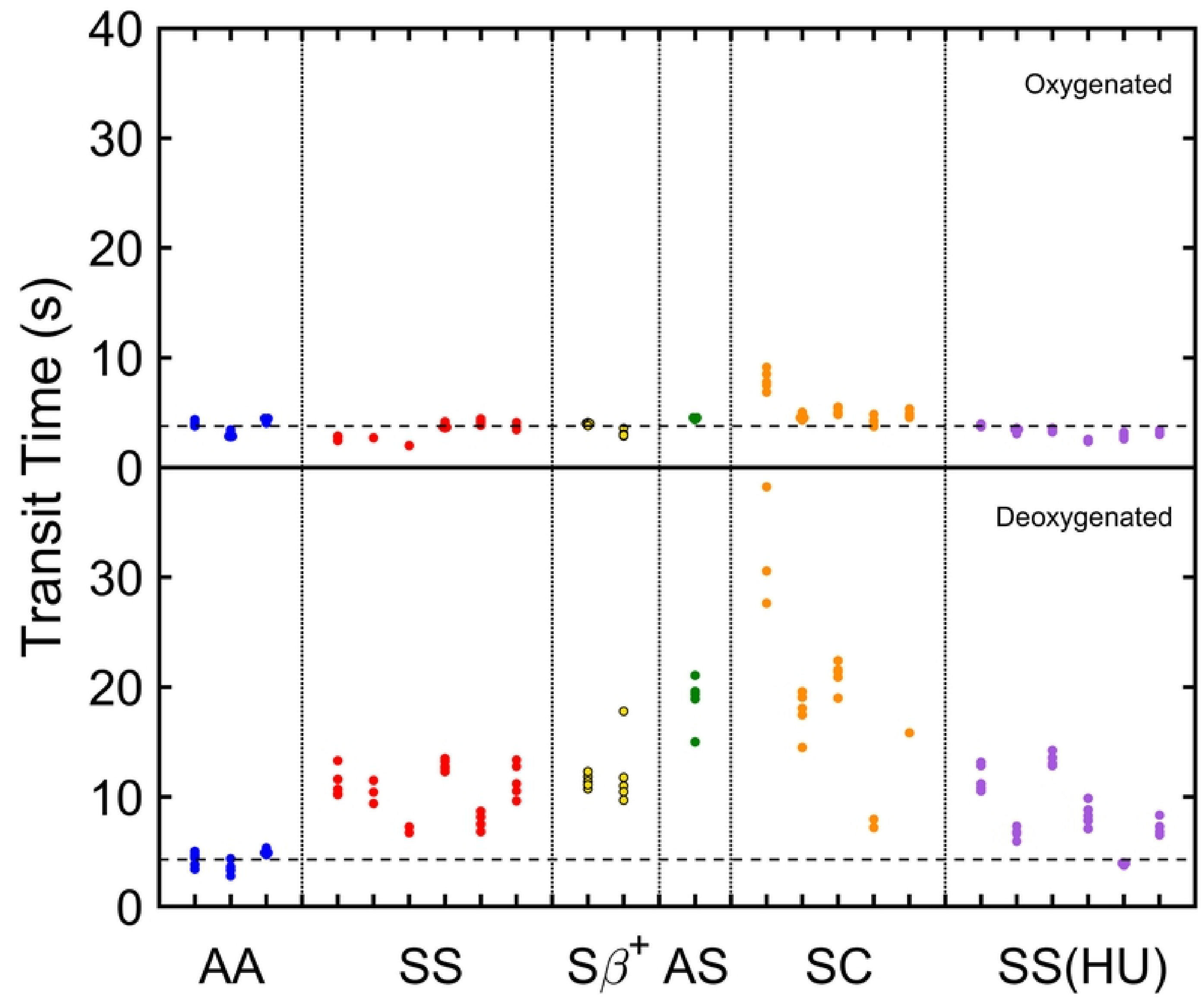

Figure 2 


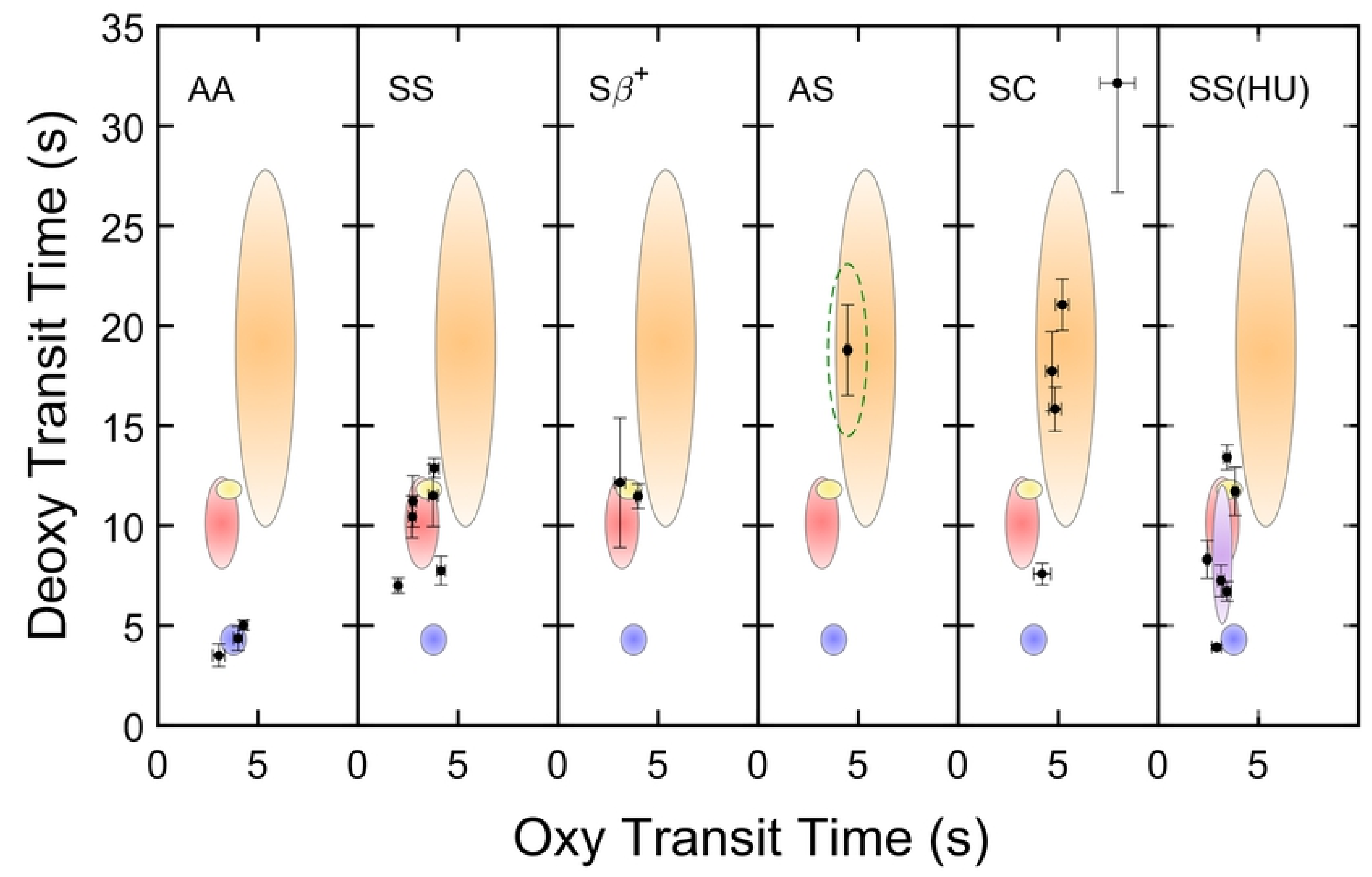

Figure 3 


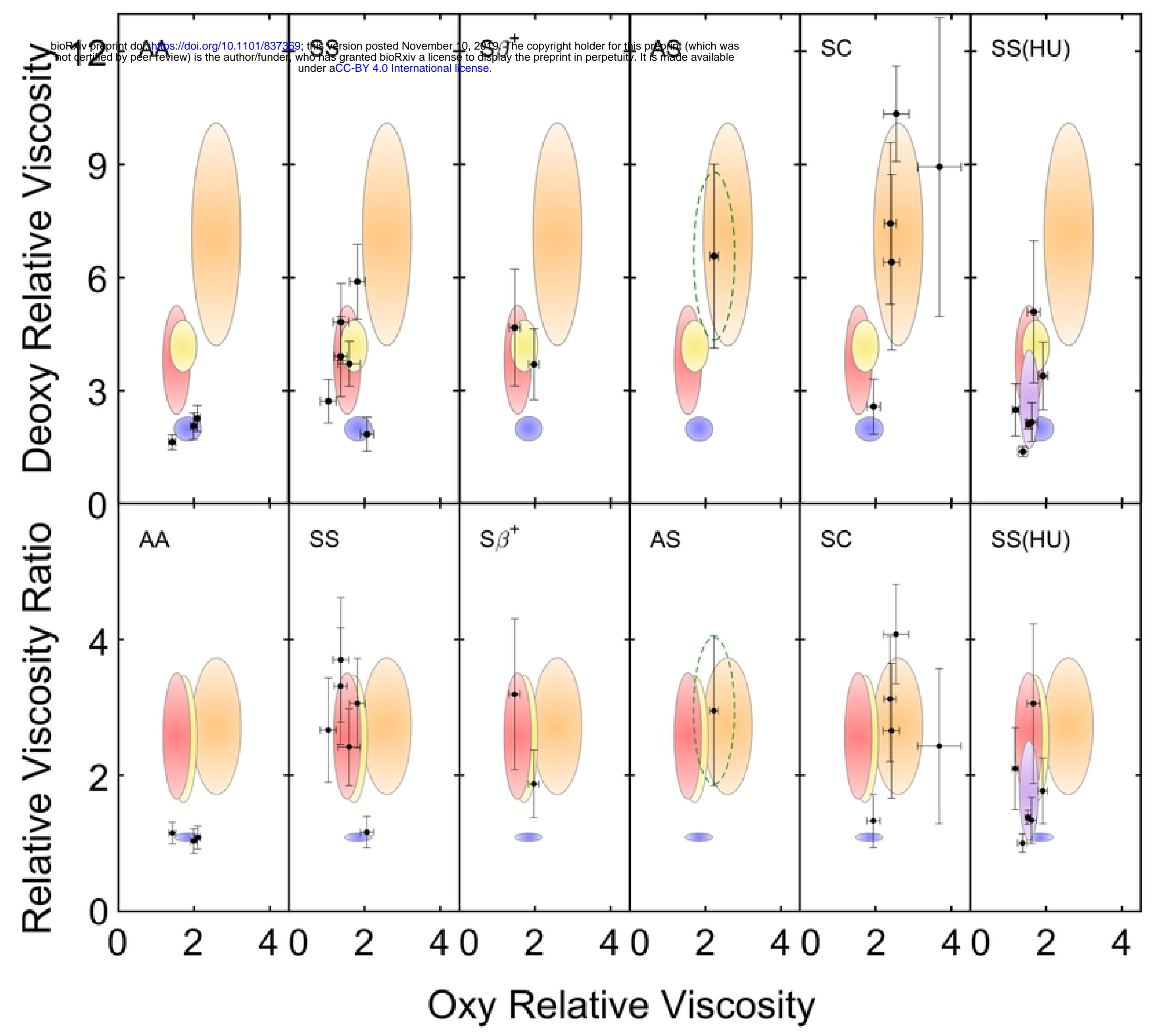

Figure 4 